Pacific Journal of Mathematics

SOME EXTREMAL PROPERTIES OF LINEAR COMBINATIONS 


\title{
SOME EXTREMAL PROPERTIES OF LINEAR COM- BINATIONS OF KERNELS ON RIEMANN SURFACES
}

\author{
Georges G. WeILl
}

1. Introduction. Let $\Gamma_{a}$ be the Hilbert space of analytic differentials of finite Dirichlet norm on an open Riemann surface. We shall consider analytic singularities which are finite linear combinations of elements of the type

$$
s_{j} d z=\sum_{k=0}^{\infty} \frac{c_{k}^{j} d z}{\left(z-\xi_{j}\right)^{k+2}}+\frac{d^{j} d z}{z-\xi_{j}}
$$

Let

$$
s d z=\sum_{j=1}^{N} s_{j} d z, \quad \sum_{j=1}^{N} d^{j}=0 .
$$

To a given singularity $s d z$ there correspond Bergman kernels

$$
k_{s}(z, \zeta) d z \text { and } h_{s}(z, \zeta) d z
$$

for the space $\Gamma_{a}$.

We now consider various subspaces $\Gamma_{a} \subset \Gamma_{a}$, and show that linear combinations of the kernels for $\Gamma_{\alpha}$ of the form

$$
h_{s} d z+\lambda k_{s} d z
$$

where $\lambda$ is complex, extremalize an explicity given functional.

We proved in our thesis [2] that, for the space $\Gamma_{a e}$ of analytic exact differentials on a planar Riemann surface,

$$
\begin{aligned}
& k_{s} d z=\frac{1}{2} \frac{\partial}{\partial z}\left(p_{1}-p_{0}\right) d z \\
& h_{s} d z=\frac{1}{2} \frac{\partial}{\partial z}\left(p_{1}+p_{0}\right) d z
\end{aligned}
$$

where $p_{1}$ and $p_{0}$ are Sario's principal functions with the corresponding singularities [1, Chapter III].

Here we show that the right hand sides still enjoy the same properties on an arbitrary Riemann surface, for the subspace $\Gamma_{p} \cap \Gamma_{a s e}$, where $\Gamma_{a s e}=\left\{a d z: a d z \in \Gamma_{a}, \int_{\gamma} a d z=0, \gamma\right.$ any dividing cycle $\}$, and $\Gamma_{p}$ is generated over the complex numbers by $\left\{\Gamma_{p}\right\}=\{a d z: a d z=\partial p / \partial z, p$ a single-valued harmonic function on $W$, with finite Dirichlet integral.\}

Received August 21, 1961. 
2. Inner products and singular differentials. We shall be concerned here with the Hilbert space $\Gamma_{a}$ of analytic differentials on a given Riemann surface $W$. The inner product of two analytic differentials $a d z=\alpha d x+\beta d y$ and $a_{1} d z=\alpha_{1} d x+\beta_{1} d y$ is defined as:

$$
\left(a d z, a_{1} d z\right)_{W}=-i \int_{W} a \bar{a}_{1} d z \overline{d z}=\int_{W}\left(\alpha \bar{\alpha}_{1}+\beta \bar{\beta}_{1}\right) d x d y .
$$

If we now consider differentials analytic on $W$, except for a singularity of the type $d z /(z-\zeta)^{m+2}, m \geqq 0$, we delete a disk $\delta$ of radius $r$ about $z=\zeta$ and define for differentials $b d z$ and $b_{1} d z$ analytic except for a singularity of the above type, the inner product

$$
\left(b d z, b_{1} d z\right)_{W}=\lim _{r \rightarrow 0}\left(b d z, b_{1} d z\right)_{W-\delta},
$$

which amounts to considering the Cauchy principal value for the inner product. In the case of a singularity $d z /\left(z-\zeta_{1}\right)-d z /\left(z-\zeta_{2}\right)$, we replace $\delta$ by disks about $z=\zeta_{1}$ and $z=\zeta_{2}$, plus a narrow strip along a cut joining $z=\zeta_{1}$ to $z=\zeta_{2}$ and define in the same fashion the inner product by a Cauchy limit.

The previous remarks may be extended to finite linear combinations of singularities of the type

$$
s_{j} d z=\sum_{k=0}^{\infty} \frac{c_{k}^{j} d z}{\left(z-\zeta_{j}\right)^{k+2}}+\frac{d^{j} d z}{\left(z-\zeta_{\jmath}\right)}
$$

provided $\sum_{j=1}^{N} d^{j}=0$.

3. Extremal properties of the kernels. Let $s d z=\sum_{j=1}^{N} s_{j} d z$ be a singularity differential and $k_{s} d z, h_{s} d z$ be the Bergman kernels correspond to that singularity. We shall consider linear combinations

$$
\left(h_{s}+\lambda k_{s}\right) d z
$$

which are normalized in the sense that they all exhibit the same singularity.

We recall that for $l(z) d z \in \Gamma_{a}$, the Bergman kernels corresponding to a singularity $s d z$, enjoy the following properties:

$$
\begin{aligned}
& \text { for } s d z=\frac{d z}{(z-\zeta)^{m+2}}, m \geqq 0\left(l d z, k_{s} d z\right)=\frac{2 \pi l^{(m)}(\zeta)}{(m+1) !} \\
& \text { for } s d z=\frac{d z}{z-\zeta_{1}} \frac{d z}{z-\zeta_{2}}\left(l d z, h_{s} d z\right)=0 \\
&\left(l d z, k_{s} d z\right)=-\left(l d z, h_{s} d z\right)^{\prime}=\left\{2 \pi \int_{c} l d z\right.
\end{aligned}
$$

where $c$ is a path from $\zeta_{1}$ to $\zeta_{2}$.

For $s d z=a s_{1} d z+b s_{2} d z,(a, b$ constant), 


$$
\begin{aligned}
& k_{s} d z=a k_{s 1} d z+b k_{s 2} d z \\
& h_{s} d z=a h_{s 1} d z+b h_{s 2} d z .
\end{aligned}
$$

Such a linear property is a consequence of the uniqueness of the kernels. Notice that in particular: $\left(l d z, k_{s} d z\right)=\bar{a}\left(l d z, k_{s 1} d z\right)+\bar{b}\left(l d z, k_{s 2} d z\right)$. Let now $a_{s} d z$ be a differential, analytic except for the singularity $s d z$. We form

$$
\begin{gathered}
\left\|a_{s} d z-\left(h_{s}+\lambda k_{s}\right) d z\right\|^{2}=\left\|a_{s} d z\right\|^{2}-\left\|h_{s} d z\right\|^{2}+|\lambda|^{2}\left\|k_{s} d z\right\|^{2} \\
\quad+2 \operatorname{Re}\left(\left(h_{s}-a_{s}\right) d z, h_{s} d z\right)+2 \operatorname{Re} \bar{\lambda}\left(\left(h_{s}-a_{s}\right) d z, k_{s} d z\right) .
\end{gathered}
$$

Assume now that in a disk about $z=\zeta_{j}$

$$
\begin{aligned}
& h_{s} d z=s_{j} d z+\sum_{k=0}^{\infty} b_{k}^{j}\left(z-\zeta_{j}\right)^{k} d z \\
& a_{s} d z=s_{j} d z+\sum_{k=0}^{\infty} a_{k}^{j}\left(z-\zeta_{j}\right)^{k} d z .
\end{aligned}
$$

We then compute:

$$
\begin{gathered}
2 \operatorname{Re}\left(\left(h_{s}-a_{s}\right) d z, h_{s} d z\right)=-4 \pi \sum_{j=1}^{N} \operatorname{Re} \bar{d}^{j} \int_{c_{j}}\left(h_{s}-a_{s}\right) d z \\
2 \operatorname{Re} \bar{\lambda}\left(\left(h_{s}-a_{s}\right) d z, k_{s} d z\right)=4 \pi \sum_{j=1}^{N} \operatorname{Re} \bar{\lambda}\left[\sum_{k=1}^{\infty} \frac{\left(b_{k}^{j}-a_{k}^{j}\right) \bar{c}_{k}^{j}}{k+1}+\bar{d}^{j} \int_{c_{j}}\left(h_{s}-a_{s}\right) d z\right.
\end{gathered}
$$

using the linear property of the kernels, with respect to the coefficients of the singularity. We now write (1) in the following form:

$$
\begin{gathered}
\left\|a_{s} d z\right\|^{2}-4 \pi \sum_{j=1}^{N} \operatorname{Re}\left[\sum_{k=0}^{\infty} \frac{\bar{\lambda} a_{k}^{j} \bar{c}_{k}^{j}}{k+1}+(\bar{\lambda}-1) \bar{d}_{j} \int_{c_{j}}\left(a_{s}-s\right) d z\right]=\left\|h_{s} d z\right\|^{2} \\
-|\lambda|^{2}\left\|k_{s} d z\right\|^{2}-4 \pi \sum_{j=1}^{N} \operatorname{Re}\left[\sum_{k=0}^{\infty} \frac{\bar{\lambda} b_{k}^{j} \bar{c}_{k}^{j}}{k+1}+(\bar{\lambda}-1) \bar{d}^{j} \int\left(h_{s}-s\right) d z\right] \\
+\left\|a_{s} d z-\left(h_{s}+\lambda k_{s}\right) d z\right\|^{2} .
\end{gathered}
$$

We can now study the value of the bracket in the functional, and prove that

$$
\sum_{j=1}^{N}\left[\sum_{k=0}^{\infty} \frac{\bar{\lambda} b_{k}^{j} \bar{c}_{k}^{j}}{k+1}+\bar{\lambda} \bar{d}^{j} \int_{c_{j}}\left(h_{s}-s\right) d z\right]=0
$$

We shall summarize our results in a theorem:

Theorem III A. Let $s d z=\sum_{j=1}^{N} s_{j} d z$ where

$$
s_{j} d z=\sum_{k=0}^{\infty} \frac{c_{k}^{j} d z}{\left(z-\zeta_{j}\right)^{k+2}}+\frac{d^{j} d z}{\left(z-\zeta_{j}\right)}
$$

be an analytic singularity with $\sum_{j=1}^{N} d^{j}=0$. 
Let $k_{s} d z, h_{s} d z$ be the Bergman kernels corresponding to $s d z$, and let $\lambda$ be a complex parameter.

Then the linear combination $\left(h_{s}+\lambda k_{s}\right) d z$ minimizes the functional:

$$
\left\|a_{s} d z\right\|^{2}-4 \pi \sum_{j=1}^{N} R e\left[\sum_{k=0}^{\infty} \frac{\bar{\lambda} a_{k}^{j} \bar{c}_{k}^{j}}{k+1}+(\bar{\lambda}-1) \bar{d}^{j} \int_{c_{j}}\left(a_{s}-s\right) d z\right]
$$

over the class of differentials $a_{s} d z$, analytic except for the singularity $s d z$. The minimum is

$$
\left\|h_{s} d z\right\|^{2}+4 \pi \sum_{j=1}^{N} \operatorname{Re} \bar{d}^{j} \int_{\sigma_{j}}\left(h_{s}-s\right) d z+|\lambda|^{2}\left\|k_{s} d z\right\|^{2},
$$

and the deviation from the minimum is

$$
\left\|a_{s} d z-\left(h_{s}+\lambda k_{s}\right) d z\right\|^{2} \text {. }
$$

Proof. $h_{s} d z+\lambda e^{i \theta} k_{s} d z$ for $\theta$ real is a competing function; therefore:

$$
\begin{gathered}
\left\|h_{s} d z\right\|^{2}-|\lambda|^{2}\left\|k_{s} d z\right\|^{2}-4 \pi \sum_{j=1}^{N} \operatorname{Re}\left[\sum_{k=0}^{\infty} \frac{\bar{\lambda} \bar{c}_{k}^{j} b_{k}^{j}}{k+1}+(\bar{\lambda}-1) \bar{d}^{j} \int_{c_{j}}\left(h_{s}-s\right) d z\right] \\
\leqq\left\|h_{s} d z\right\|^{2}-|\lambda|^{2}\left\|k_{s} d z\right\|^{2}-4 \pi \sum_{j=1}^{N}\left[\sum_{k=1}^{\infty} \frac{\bar{\lambda} e^{-i \theta} \bar{c}_{k}^{j} \bar{b}_{k}^{j}}{k+1}\right. \\
\left.+\left(\bar{\lambda} e^{-i \theta}-1\right) \overline{d^{j}} \int_{c j}\left(h_{s}-s\right) d z\right] .
\end{gathered}
$$

It follows that

$$
\begin{aligned}
\sum_{j=1}^{N} \operatorname{Re}\left[\sum_{k=0}^{\infty} \frac{\bar{\lambda} \bar{c}_{k}^{j} b_{k}^{j}}{k+1}+\right. & \left.\bar{\lambda} \bar{d}^{j} \int_{c_{j}}\left(h_{s}-s\right) d z\right] \\
& \geqq \sum_{j=1}^{N} \operatorname{Re}\left\{e^{-i \theta}\left[\sum_{k=0}^{\infty} \frac{\bar{\lambda} \bar{c}_{k}^{j} b_{k}^{j}}{k+1}+\bar{\lambda} d^{j} \int_{c_{j}}\left(h_{s}-s\right) d z\right]\right\}
\end{aligned}
$$

which is only possible if the bracket is real. It cannot be real fer all $\lambda$ except if it is equal to zero.

4. Particular cases-applications. Assume now that $a d z=(\partial p / \partial z) d z$, where $p$ is a single-valued harmonic function on $W$, except for a singularity $\operatorname{Re} S(z)=\sum_{j=1}^{N} \operatorname{Re} S_{j}(z)$, with

$$
\operatorname{Re} S_{j}(z)=d^{j} \log \left|z-\zeta_{j}\right|+\operatorname{Re}\left[\sum_{k=0}^{\infty} \frac{c_{k}^{j}}{(-k-1)\left(z-\zeta_{j}\right)^{k+1}}\right],
$$

where $d^{j}$ is real. The singularity of $(\partial p / \partial z) d z$ is then $s d z=\sum_{j=1}^{N} s_{j} d z$, with

$$
s_{j} d z=\frac{d^{j} d z}{z-\zeta_{j}}+\sum_{k=0}^{\infty} \frac{c_{k}^{j} d z}{\left(z-\zeta_{j}\right)^{k+2}}
$$


Moreover if $p=\operatorname{Re}\left\{S_{j}(z)+\sum_{k=0}^{\infty} A_{k}^{j}\left(z-\zeta_{j}\right)^{k}\right\}$ near $z=\zeta_{j}$ and

$$
\frac{\partial p}{\partial z} d z=s_{j} d z+\sum_{k=0}^{\infty} a_{k}^{j}\left(z-\zeta_{j}\right)^{k}
$$

it follows that $A_{k+1}^{j}=a_{k}^{j} / k+1$ for $k \geqq 0$. We notice furthermore that $\|a d z\|^{2}=2(B(p)-A(p))$, where $B(p)=\int_{\beta} p d p^{*}$ ( $\beta$ the ideal boundary of $\omega)$ and $A(p)=2 \pi \sum_{j=1}^{N} d^{j} \int_{c_{j}}\left(a_{s}-s\right) d z$. The functional to be minimized becomes:

$$
2\left[B(p)-2 \pi \sum_{j=1}^{N} R e\left[\sum_{k=0}^{\infty} \frac{\bar{\lambda} a_{k}^{j} \bar{c}_{k}^{j}}{k+1}+\bar{\lambda} d^{j} \int_{c_{j}}\left(a_{s}-s\right) d z\right]\right] .
$$

We notice that the differentials $a d z=(\partial p / \partial z) d z$ with $p$ single valued harmonic function generate a subspace $\Gamma_{p} \subset \Gamma_{a}$. If $k_{s p} d z$ and $h_{s p} d z$ are the Bergman kernels for $\Gamma_{p}$, they correspond to two functions $K_{s}$ harmonic and $H_{s}$ harmonic except for the singularity $\operatorname{Re} S(z)$ and such that:

$$
\begin{aligned}
& k_{s p} d z=\frac{\partial K_{s}}{\partial z} d z \\
& h_{s p} d z=\frac{\partial H_{s}}{\partial z} d_{s} .
\end{aligned}
$$

We can write the value of the minimum as:

$$
2 B\left(H_{s p}\right)+|\lambda|^{2}\left\|k_{s p} d z\right\|^{2} \text {. }
$$

We now shall prove the following theorem.

THEOREM IV A: Let $\left(\partial_{p_{0}} / \partial z\right) d z$ and $\left(\partial_{p_{1}} / \partial z\right) d z$ be the analytic differentials with singularity sdz, corresponding to the principal functions $p_{0}$ and $p_{1}$. Then

$$
\begin{aligned}
& \frac{1}{2} \partial / d z\left(p_{1}-p_{0}\right) d z=k_{s p} d z \\
& \frac{1}{2} \partial / d z\left(p_{1}+p_{0}\right) d z=h_{s p} d z,
\end{aligned}
$$

where $h_{s p} d z$ and $k_{s p} d z$ are the orthogonal and reproducing kernels for $\Gamma_{p} \cap \Gamma_{a s e}$, corresponding to the singularity sdz.

Proof. First, we know from the definition of $p_{0}$ and $p_{1}$, that $\left(\partial_{p 0} / \partial z\right) d z$ and $\left(\partial_{p 1} / \partial z\right) d z$ are elements of $\Gamma_{p} \cap \Gamma_{a s e}$. Second, from (1. Chapter III. Theorem $9 \mathrm{E}$ where only the notation is different), $\left(\partial_{p 0} / \partial z\right) d z$ minimizes the same functional as $h_{s p} d z-k_{s p} d z$ (which corresponds to $\lambda=-1)$, and $\left(\partial_{p 1} / \partial z\right) d z$ minimizes the same functional as $\left(h_{s p} d z+k_{s p}\right) d z$, (which corresponds to $\lambda=1$ ). The theorem follows.

We shall consider here a family of functions $P$ harmonic, except 
for a singularity of the type $\operatorname{Re} S(z)$; the periods of $P$ vanish along all dividing cycles. It follows that the differentials $(\partial P / d z) d z$ are elements of $\Gamma_{P} \cap \Gamma_{a s e}$, except for a singularity $s(z) d z$.

We shall call $H_{s}$ the function corresponding to $h_{s p} d z$, and $K_{s}$ the one corresponding to $k_{s p} d z$. The following results are consequences of the main Theorem.

THEOREM IV B: Among all functions $P$ with singularity $1 /(z-\zeta)$, $H_{s}+\lambda K_{s}$ minimizes the functional $B(P)-2 \pi R e \bar{\lambda} A_{1}$.

THEOREM IV C: Among all functions $P$ with singularity $\log \left|\left(z-\zeta_{1}\right)\right|$ $\left(z-\zeta_{2}\right) \mid, H_{s}+\lambda K_{s}$ minimizes $B(P)-2 \pi \operatorname{Re} \bar{\lambda}\left(A_{0}^{1}-A_{0}^{2}\right)$.

Theorem IV D: Among all functions $P$ with singularity $\operatorname{ReS}(z)$, $H_{s}$ minimizes the functional $B(P)$.

We shall now consider exact differentials, analytic except for some singularity $s(z) d z=\sum_{j=1}^{N} s_{j}(z) d z$, which may be written $f^{\prime}(z) d z=d f(z)$, where $f$ is a function analytic except for a singularity $S(z)=\sum_{j=1}^{N} s_{j}(z)$ such that $S^{\prime}(z) d z=s(z) d z$; then $f=S_{j}(z)+\sum_{k=0}^{\infty} \alpha_{k}\left(z-\zeta_{j}\right)^{k}$ near $z=\zeta_{j}$. We proved [II] the existence of a non-zero reproducing kernel if $W \notin 0_{A D}$. We shall now find a sufficient condition for the existence of an orthogonal kernel. We recall that in the case of a planar Riemann surface

$$
\Gamma_{h}=\Gamma_{h e}+\Gamma_{h e}^{*} \cap \Gamma_{h o}^{*} .
$$

We shall consider here Riemann surfaces on which

$$
\Gamma_{h}=\Gamma_{h e}+\Gamma_{h e}^{*} .
$$

We call such surfaces type $W_{E}$. On a surface of type $W_{E}$

$$
\Gamma_{h 0} \cap \Gamma_{h o}^{*}=\left[\Gamma_{h e}+\Gamma_{h e}^{*}\right]^{\perp}=0 .
$$

We then get the following lemma:

LEMmA IV E: On a surface of type $W_{E}$, given a singularity $s(z) d z=d z /(z-\zeta)^{m+2}, m \geqq 0$, there exists a differential analytic exact, except for the corresponding singularity.

Proof. Let $\Theta$ be constructed as in [1, Chapter V. 18.19]. The differential $\Theta-i \Theta^{*}$ is square integrable and hence has the decomposition?.

$$
\Theta-i \Theta^{*}=\omega_{h}+\omega_{e o}+\omega_{e o}^{*}=\omega_{h e}+\omega_{h e}^{*}+\omega_{e o}+\omega_{e o}^{*} .
$$

It follows that

$$
\eta=\Theta-\omega_{e o}-\omega_{h e}=i \Theta^{*}+\omega_{h e}^{*}+\omega_{e o}^{*}
$$


is harmonic exact except for the singularity and so is $\eta^{*}$. We may write $\eta=\phi+\bar{\psi}$ where $\psi$ is analytic and $\phi$ is analytic except for the singularity. It follows that $\phi$ is the differential mentioned in the lemma; $\phi=d F_{m}$ where $F_{m}$ is an analytic function except for the singularity

$$
\frac{-1}{(m+1)(z-\zeta)^{m+1}}
$$

and from [2] there exists an orthogonal kernel $d H_{m}$ for $\Gamma_{a e}$ on $W_{E}$.

Note. An analogous proof works for differentials with $s(z) d z=$ $d z /\left(z-\zeta_{1}\right)-d z /\left(z-\zeta_{2}\right)$; we have only to discard the periods about $z=\zeta_{1}$ and $z=\zeta_{2}$.

From the existence of orthogonal kernels for $\Gamma_{a e}$ we can state the following theorems; here $B(f)=\frac{1}{2} \int_{\beta} f d \bar{f} ; H_{s}$ and $K_{s}$ are analytic functions whose differentials are respectively the orthogonal and reproducing kernels for $\Gamma_{a e}$, corresponding to the singularity.

THEOREM IV F: Among all functions $f$ analytic except for a simple pale at $z=\zeta$ with expansion $f=c_{1} /(z-\zeta)+\alpha_{1}(z-\zeta)+\cdots$ in a neighborhood of $z=\zeta, H_{s}+\lambda K_{s}$ minimizes the functional $B(f)+$ $2 \pi R e \bar{\lambda} \bar{c}_{1} \alpha_{1}$.

Theorem IV G: Among all functions $f(z)$ analytic except for the singularity

$$
S(z)=\sum_{j=1}^{N} \sum_{k=0}^{\infty} \frac{c_{k}^{j}}{\left(z-\zeta_{j}\right)^{k+1}(-k-1)},
$$

the function $H_{s}$ minimizes $B(f)$.

\section{BIBLIOGRAPHY}

1. L. V. Ahlfors and L. Sario, Riemann surfaces, Princeton University Press, Princeton 1960.

2. G. G. Weill, Reproducing kernels and orthogonal kernels for analytic differentials on Riemann surfaces, Pacific J. Math., 12 (1962), 729-767. 



\section{PACIFIC JOURNAL OF MATHEMATICS}

\section{EDITORS}

\author{
Ralph S. Phillips \\ Stanford University \\ Stanford, California \\ M. G. Arsove \\ University of Washington \\ Seattle 5 , Washington
}

\author{
A. L. Whiteman \\ University of Southern California \\ Los Angeles 7, California \\ Lowell J. Paige \\ University of California \\ Los Angeles 24, California
}
E. F. BECKENBACH
D. DERRY
ASSOCIATE EDITORS
T. M. CHERRY
M. OHTSUKA
H. L. ROYDEN
E. G. STRAUS
E. SPANIER
F. WOLF

\section{SUPPORTING INSTITUTIONS}

\author{
UNIVERSITY OF BRITISH COLUMBIA \\ CALIFORNIA INSTITUTE OF TECHNOLOGY \\ UNIVERSITY OF CALIFORNIA \\ MONTANA STATE UNIVERSITY \\ UNIVERSITY OF NEVADA \\ NEW MEXICO STATE UNIVERSITY \\ OREGON STATE UNIVERSITY \\ UNIVERSITY OF OREGON \\ OSAKA UNIVERSITY \\ UNIVERSITY OF SOUTHERN CALIFORNIA
}

\author{
STANFORD UNIVERSITY \\ UNIVERSITY OF TOKYO \\ UNIVERSITY OF UTAH \\ WASHINGTON STATE UNIVERSITY \\ UNIVERSITY OF WASHINGTON \\ AMERICAN MATHEMATICAL SOCIETY \\ CALIFORNIA RESEARCH CORPORATION \\ SPACE TECHNOLOGY LABORATORIES \\ NAVAL ORDNANCE TEST STATION
}

Mathematical papers intended for publication in the Pacific Journal of Mathematıcs should be typewritten (double spaced), and the author should keep a complete copy. Manuscripts may be sent to any one of the four editors. All other communications to the editors should be addressed to the managing editor, L. J. Paige at the University of California, Los Angeles 24, California.

50 reprints per author of each article are furnished free of charge; additional copies may be obtained at cost in multiples of 50 .

The Pacific Journal of Mathematics is published quarterly, in March, June, September, and December. Effective with Volume 13 the price per volume (4 numbers) is $\$ 18.00$; single issues, $\$ 5.00$. Special price for current issues to individual faculty members of supporting institutions and to individual members of the American Mathematical Society: $\$ 8.00$ per volume; single issues $\$ 2.50$. Back numbers are available.

Subscriptions, orders for back numbers, and changes of address should be sent to Pacific Journal of Mathematics, 103 Highland Boulevard, Berkeley 8, California.

Printed at Kokusai Bunken Insatsusha (International Academic Printing Co., Ltd.), No. 6, 2-chome, Fujimi-cho, Chiyoda-ku, Tokyo, Japan.

PUBLISHED BY PACIFIC JOURNAL OF MATHEMATICS, A NON-PROFIT CORPORATION

The Supporting Institutions listed above contribute to the cost of publication of this Journal, but they are not owners or publishers and have no responsibility for its content or policies. 


\section{Pacific Journal of Mathematics}

\section{Vol. 12 , No. 4 \\ April, 1962}

Tsuyoshi Andô, On fundamental properties of a Banach space with a cone ..... . 1163

Sterling K. Berberian, A note on hyponormal operators ................ 1171

Errett Albert Bishop, Analytic functions with values in a Frechet space . . . . . . . 1177

(Sherman) Elwood Bohn, Equicontinuity of solutions of a quasi-linear equation ............................................ 1193

Andrew Michael Bruckner and E. Ostrow, Some function classes related to the class of convex functions . . . . . . . . . . . . . . . . . . . . . . . . 1203

J. H. Curtiss, Limits and bounds for divided differences on a Jordan curve in the complex domain . . ................................. 1217

P. H. Doyle, III and John Gilbert Hocking, Dimensional invertibility . . . . . . . . 1235

David G. Feingold and Richard Steven Varga, Block diagonally dominant matrices and generalizations of the Gerschgorin circle theorem ................. 1241

Leonard Dubois Fountain and Lloyd Kenneth Jackson, A generalized solution of the boundary value problem for $y^{\prime \prime}=f\left(x, y, y^{\prime}\right) \ldots \ldots \ldots \ldots \ldots \ldots \ldots \ldots \ldots$

Robert William Gilmer, Jr., Rings in which semi-primary ideals are primary. . . . . 1273

Ruth Goodman, K-polar polynomials .......................... 1277

Israel Halperin and Maria Wonenburger, On the additivity of lattice completeness ........................................... 1289

Robert Winship Heath, Arc-wise connectedness in semi-metric spaces . . . . . . . . 1301

Isidore Heller and Alan Jerome Hoffman, On unimodular matrices . . . . . . . . . . . 1321

Robert G. Heyneman, Duality in general ergodic theory . . . . . . . . . . . . . . . 1329

Charles Ray Hobby, Abelian subgroups of p-groups . . . . . . . . . . . . . . . 1343

Kenneth Myron Hoffman and Hugo Rossi, The minimum boundary for an analytic

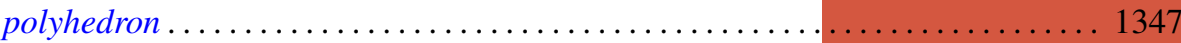

Adam Koranyi, The Bergman kernel function for tubes over convex cones ........ 1355

Pesi Rustom Masani and Jack Max Robertson, The time-domain analysis of a continuous parameter weakly stationary stochastic proces.

William Schumacher Massey, Non-existence of almost-complex structures on

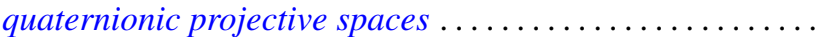

Deane Montgomery and Chung-Tao Yang, A theorem on the action of $\mathrm{SO}(3) \ldots . .1385$

Ronald John Nunke, A note on Abelian group extensions . . . . . . . . . . . . . 1401

Carl Mark Pearcy, A complete set of unitary invariants for operators generating finite $W^{*}$-algebras of type $I$

Edward C. Posner, Integral closure of rings of solutions of linear differential equations.

Duane Sather, Asymptotics. III. Stationary phase for two parameters with an application to Bessel functions.

J. Śladkowska, Bounds of analytic functions of two complex variables in domains

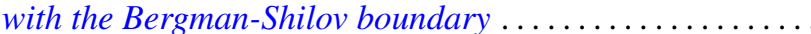

Joseph Gail Stampfli, Hyponormal operators .

George Gustave Weill, Some extremal properties of linear combinations of kernels

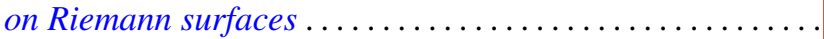

